Original Article

\title{
Hematological Profile of Patients with Dementia in South Punjab
}

\author{
Faiza Khalil ${ }^{1}$, Noreen Samad ${ }^{1}$, Sohaib Hassan ${ }^{2}$, Muhammad Ali Qureshi $^{2}$, Ahsan Numan ${ }^{3}$ \\ ${ }^{1}$ Department of Biochemistry, Bahauddin Zakariya University (BZU), ${ }^{2}$ Department of Neurology, Nishtar \\ Medical University (NMU), Multan, ${ }^{3}$ Department of Neurology, King Edward Medical University (KEMU), \\ Lahore - Pakistan
}

\begin{abstract}
Objectives: A case-control study was conducted to find the prevalence of abnormal blood indices and electrolytes in patients with dementia.

Material \& Methods: The levels of erythrocytes, leukocytes, platelets, electrolytes, and ESR were determined from the biochemistry lab. A t-test was applied to see the significance of the difference between each dementia patient group (Alzheimer Disease-AD, Parkinson's Disease-PD, and Frontotemporal Dementia-FTD) with the control group for each $C B C$ and electrolyte parameter.

Results: In each patients' groups (AD, PD, and FTD), the mean value of every erythrocyte was lower than the normal range. A significant difference existed for each erythrocyte between dementia patients and controls, except MCHC. Low levels were observed in neutrophils in all groups of dementia including control group. Very high levels were observed in ESR in all groups of dementia. Significant differences existed in the WBC levels between controls and AD as well as PD patients, in platelets between the control group and FTD patients, and in ESR in each group of dementia patients vs. control group. Normal values observed in all groups of dementia patients as well as in the control group. Significant differences existed for sodium and potassium levels between the control group and frontotemporal dementia cases.

Conclusion: We found low levels in erythrocytes in cases of Alzheimer disease, Parkinson's disease, and frontotemporal dementia. Age-related changes to hematological indices especially related to RBCs, and inflammatory mediators like cytokines, hamper the microcirculation in the cerebral tissue leading to microinfarcts or microbleeds which cause neuronal insults and parenchymal damage.
\end{abstract}

Keywords: Alzheimer Disease-AD, Parkinson's Disease-PD, Frontotemporal Dementia-FTD, Erythrocytes, Leukocytes, Electrolytes.

Corresponding Author: Faiza Khalil

Department of Biochemistry, Bahauddin Zakariya University

(BZU), Multan - Pakistan

Date of Submission: 30-04-2021

Date of Revision: 19-05-2021

Date of Online Publishing: 13-06-2021

Date of Print: 30-06-2021

DOI: 10.36552/pjns.v25i2.538

\section{INTRODUCTION}

The current study was performed on dementia patients from the South Punjab Population of Pakistan to assess and compare the levels of erythrocytes, leukocytes, and electrolytes with the healthy control group. Dementia is a neurological disorder common in the elderly population. People suffer from cognitive and behavioral 
changes and a varying degree of memory impairment. Up to $18 \%$ of the population (around 50 million people) of the world goes into neuropsychiatric disorders. They deteriorate in their thinking, memory, emotional and social behavior. $70 \%$ of the dementia of the world is attributed to Alzheimer's disease. This disease taxes heavily on the economy and psychology of the caretakers and families of the patients. ${ }^{1-3}$ Common neurodegenerative diseases are Alzheimer's disease (AD), Huntington's disease, Frontotemporal dementia (FTD), and Parkinson's disease (PD).

The many causes of dementia include hypothyroidism, vitamin deficiencies, chronic alcohol abuse, brain tumors, subdural hematomas, psychiatric, depression, traumatic brain injury, infections (HIV), and chemotherapyrelated cognitive dysfunction. ${ }^{1-4}$

Dementia prevails in the elderly and goes proportionally with advancing age. Over 94 years of age, nearly $58 \%$ of people get dementia. Dementia is not always irreversible. Newer interventions are helpful. The highest degree of clinical expertise is crucial to manage and properly recognize the neuropsychiatric symptoms of dementia. ${ }^{4}$ People with dementia develop symptoms due to neurochemical, neuropathological, and genetic factors. They develop Apraxia, which is an inability to perform previously learned tasks. The impaired executive function of judgment, reasoning, planning, and Agnosia. The cerebral cortex suffers from inflammation, following injury. Synaptic function and metabolism of neurons decline to lead to cognitive impairment. ${ }^{5-6}$ Dementia's early phase slowly progresses and goes overlooked. The patient is forgetful, generally confused in time and space. In the middle phase, the symptoms are more defined and obvious to the caregivers. Patients experience uneasy swallowing of food, dysequilibrium, speech problems, confusion, or memory. They also report an inclusive of unease in swallowing and eating, having balance problems, language and speech difficulties, memory impairment, forgets names or events, changes in behavior, restlessness, wandering around and repeatedly questioning), forgetfulness of people's names and recent events. They often require more help with problem-solving, communication, and attention. During the last phase, memory disturbance is marked. Cannot identify nearby relatives, places, or events. There is aggressiveness, crying, or anger. $^{7-8}$

In clinical practice, behavioral and psychiatric disorders exhibit a variety of cognitive and noncognitive symptoms. Patients ultimately develop behavioral or psychiatric symptoms in over $90 \%$ of the cases of dementia. The behavioral and psychological symptoms of dementia (BPSD) includes hallucinations, anxiety, depression, agitation, disinhibition, elation, apathy, irritability, delusions, aberrant motor behavior, and appetite or sleep changes. The BPSD tends to have a poor outcome in psychiatric patients as hospital stay and health care costs come into play in the longterm sequelae of the disease. It involves the misuse of drugs, agitation, or distress of the caregivers and the patients as well. ${ }^{9-11}$ Symptoms in patients either exist simultaneously or occur individually. In clinical practice, it is better to group the symptoms of BPSD patients for estimation of prognosis, the response of treatment, and the natural course of disease ${ }^{10-11}$. The dementias have some risk factors. Age is the biggest risk factor. Symptoms increase as the age advances. First-degree relatives of Alzheimer's patients have a higher risk. The genetic component apoE4 (Apolipoprotein E) has a role to play. Other risk factor includes lifestyle, diabetes, and hypertension, the intensity of mental engagement through life, play significant role. $^{9}$

Cortical and sub-cortical types of dementia is a classification used by Psycho-neurolinguistics. Cortical dementia (CD) includes Alzheimer Disease (AD), Frontotemporal Dementia (FTD), 
Creutzfeldt-Jakob disease (CJD) while Subcortical dementia (SCD) includes Progressive supranuclear palsy, Parkinson's Disease (PD) and Huntington's Disease (HD). ${ }^{9,12}$ Parkinson's disease is a progressive neurodegenerative disorder that occurs when substantia nigra cells start dying. There is no test that persistently differentiates PD from other neuropsychiatric disorders. History and examination remain the mainstay for diagnosis. The patient has slowness and difficulty of movements and rigidity of limbs. PD can also be caused due to infarctions of the cerebrum, or its degeneration like, multiple system atrophy or progressive supranuclear palsy. ${ }^{13}$ Frontotemporal dementia (FTD) is another progressive neurodegenerative disorder when atrophy of frontal and temporal lobes occurs. Here the patient has all the common neurodegenerative symptoms along with personality change, bizarre effect, and aphasia. ${ }^{14}$ Alzheimer's disease includes the affected area affected in Alzheimer's is the medial temporal and temporoparietal cortex. It starts with memory loss. There is amyloid protein deposition outside neurons and neurofibrillary tangles inside the cells that contribute to senile plaque formation. Amyloid plaques are formed by extracellular deposition of $A \beta .^{15}$

\section{MATERIALS AND METHODS}

\section{Study Design, Setting \& Population}

A case-control study was conducted during 20182019, at Bahauddin Zakariya University (BZU), Multan, Pakistan, to find the prevalence of abnormal blood indices and electrolytes in patients with dementia disease.

\section{Inclusion Criteria}

The dementia patients ( $N=35)$ and the healthy individuals as the control group ( $N=15$ ) were enrolled from South Punjab. Following groups of dementia patients were included: Alzheimer Disease (AD), Parkinson's Disease (PD) and
Frontotemporal Dementia (FTD). Patients belonged to Kot Addu, Taunsa, Multan, Shujabad, Dera Gazi Khan, and Bahawalpur stations.

\section{Diagnosis of Dementia}

The diagnosis of dementia was done via. either MRI or CT scans. In some of the patients, the PET or SPECT scans were also conducted for the diagnosis.

\section{Exclusion Criteria}

Patients suffering from malignancies not will to become part of the study.

\section{Blood Sampling}

Blood samples of dementia patients were collected from Fatima Medical Center, Multan. The blood samples of healthy controls were also collected from Fatima Medical Center, Multan.

\section{Laboratory Testing}

The blood samples were sent to the biochemistry laboratory of Fatima Medical Center. The levels of erythrocytes, leukocytes, platelets and ESR were determined through the complete blood count (CBC) test in both patients' groups as well as in control group. Serum electrolytes (Sodium \& Potassium) were also determined from biochemistry laboratory tests.

\section{Data Collection \& Analyses}

The data was collected for the information on age, gender, location, medication intake, existence of diabetes mellitus (DM). The descriptive statistics including frequencies, mean values, minimum/maximum values were analyzed via. SPSS version 25. Each parameter of CBC and electrolytes were compared with the normal ranges. 


\section{Statistical Analyses}

A t-test was applied to see the significance of difference between each dementia patient group (AD, PD \& FTD) with the control group for each $\mathrm{CBC}$ and electrolyte parameter. A p-value less than 0.050 was considered the significant.

\section{RESULTS}

\section{Age of the Patients}

The mean age of the dementia patients was 70 years, whereas, the mean age of the control group was 65 years.

\section{Gender Distribution}

There were more female patients (62.85\%) as compared to male patients (37\%). Majority of the patients were from rural areas (51.4\%).

\section{Clinical Information}

Table 1 shows the complete detail of information for both groups. The control group was not taking any medication. Dementia patients were on medication. Both group individuals were not diabetic. The included dementia patients people were not having any other diseases. However, they were found the intake of the following drugs for dementia: Donepezil, Memantine, Quetiapine,
Table 1: Sociodemographic Information of Dementia Patients and Controls.

\begin{tabular}{|lll} 
Parameters & $\begin{array}{l}\text { Dementia Group } \\
\mathbf{N}=\mathbf{3 5}\end{array}$ & $\begin{array}{l}\text { Control Group } \\
\mathbf{N}=15\end{array}$ \\
& Mean: 70; & Mean: 65; \\
Age (years) & Minimum:60; & Minimum: 50; \\
& Maximum:80 & Maximum: 80 \\
Gender & Male: $13(37 \%) ;$ & Male: $7(46 \%) ;$ \\
& Female: $22(62.85 \%)$ & Female: 8 (53.3\%) \\
Location & Rural: $18(51.4 \%)$ & Rural: $6(40 \%)$ \\
& Urban: $17(48.5 \%)$ & Urban: $9(60 \%)$ \\
\hline
\end{tabular}

Risperidone, Donecept, Valium, Methylcobalamin, Alzilo, Sinemet and PK-Merz.

\section{Comparison of Erythrocytes}

Table 2 shows the mean values of each erythrocyte in each group of dementia patients including a control group. The control group was having normal values of almost all parameters except, hematocrit and MCHC. However, in dementia patients' groups (Alzheimer Disease, Parkinson's Disease and Frontotemporal Dementia) mean value of every erythrocyte parameter was lower than the normal range. A significant difference existed ( $p$ value $<0.050$ ) for each erythrocyte parameter between each dementia patient group (AD, PD, and FTD) and control group (Table 3), except MCHC (between controls and AD group).

Table 2: Comparison of Mean Values of Erythrocytes between of Dementia Patients and Controls.

\begin{tabular}{|c|c|c|c|c|}
\hline Erythrocytes & $\begin{array}{l}\text { Control Group } \\
\qquad \mathbf{N}=15\end{array}$ & $\begin{array}{c}\text { Alzheimer } \\
\text { Disease (AD) } \\
\text { Patients } N=12\end{array}$ & $\begin{array}{c}\text { Parkinson's } \\
\text { Disease (PD) } \\
\text { Patients } N=12\end{array}$ & $\begin{array}{c}\text { Frontotemporal } \\
\text { Dementia (FTD) } \\
\text { Patients } N=11\end{array}$ \\
\hline $\begin{array}{l}\text { Hemoglobin }(\mathrm{g} / \mathrm{dL}) \\
\text { Normal Range: } 13.5-17.5\end{array}$ & $13.7 \pm 1.64$ & $7.19 \pm 0.928$ & $8.90 \pm 1.308$ & $10.42 \pm 0.681$ \\
\hline $\begin{array}{l}\text { Hematocrit (\%) } \\
\text { Normal Range: } 42-52 \text { (male), } 37-47 \text { (female) } \\
\text { Red Blood Cells }\left(\times 10^{6} / \mu \mathrm{L}\right)\end{array}$ & $40.6 \pm 4.376$ & $27.03 \pm 4.027$ & $23.38 \pm 1.481$ & $26.4 \pm 2.79$ \\
\hline $\begin{array}{l}\text { Normal Range: } 4.5-5.9 \text { (male), } 4.1-5.1 \\
\text { (female) }\end{array}$ & $4.87 \pm 0.533$ & $2.76 \pm 0.608$ & $2.97 \pm 0.531$ & $3.06 \pm 0.485$ \\
\hline $\begin{array}{l}\text { Mean Cell Volume }(\mathrm{fL}) \\
\text { Normal Range: } 80-94\end{array}$ & $87.4 \pm 4.656$ & $71.95 \pm 4.094$ & $77.48 \pm 1.187$ & $70.09 \pm 2.213$ \\
\hline Mean Corpuscular Hemoglobin (pg) & $29.3 \pm 1.790$ & $25.09 \pm 1.195$ & $25.63 \pm 2.029$ & $25.2 \pm 2.188$ \\
\hline
\end{tabular}


Normal Range: 27.5 - 33.2

Mean Corpuscular Hemoglobin Concentration

(g/dL) Normal Range: 33.4 - 35.5

Table 3: Comparison of Erythrocytes via. t-Test.

\begin{tabular}{|c|c|c|c|c|c|c|}
\hline \multirow[t]{2}{*}{ Erythrocytes } & \multicolumn{2}{|c|}{$\begin{array}{l}\text { Control Group vs. } \\
\text { Alzheimer Disease } \\
\text { (AD) Patients }\end{array}$} & \multicolumn{2}{|c|}{$\begin{array}{l}\text { Control Group vs. } \\
\text { Parkinson's Disease } \\
\text { (PD) Patients }\end{array}$} & \multicolumn{2}{|c|}{$\begin{array}{l}\text { Control Group vs. } \\
\text { Frontotemporal Dementia } \\
\text { (FTD) Patients }\end{array}$} \\
\hline & $p$-value & t- test; df & p-value & t- test & $p$-value & t- test \\
\hline Hemoglobin (g/dL) & $<0.0001$ & $12.24 ; 25$ & $<0.0001$ & $8.24 ; 25$ & $<0.0001$ & $6.22 ; 24$ \\
\hline Hematocrit (\%) & $<0.0001$ & $11.90 ; 25$ & $<0.0001$ & $28.28 ; 25$ & $<0.0001$ & $16.30 ; 24$ \\
\hline Red Blood Cells (millon cells/cmm) & $<0.0001$ & $9.60 ; 25$ & $<0.0001$ & $9.21 ; 25$ & $<0.0001$ & $8.87 ; 24$ \\
\hline Mean Cell Volume $(\mathrm{fL})$ & $<0.0001$ & $9.03 ; 25$ & $<0.0001$ & $7.71 ; 25$ & $<0.0001$ & $11.37 ; 24$ \\
\hline Mean Corpuscular Hemoglobin (pg) & $<0.0001$ & $6.98 ; 25$ & $<0.0001$ & $4.99 ; 25$ & $<0.0001$ & $5.25 ; 24$ \\
\hline $\begin{array}{l}\text { Mean Corpuscular Hemoglobin } \\
\text { Concentration }(\mathrm{g} / \mathrm{dL})\end{array}$ & $1.000^{*}$ & $0.0 ; 25$ & 0.0028 & $3.30 ; 25$ & 0.0217 & $2.45 ; 24$ \\
\hline
\end{tabular}

*Insignificant

\section{Comparison of Leukocytes}

Table 4 shows the mean values of each leukocyte and ESR in each group of dementia patients including a control group. Normal ranges were observed between white blood cells, eosinophils, and platelets in all groups of dementia patients including the control group. Low levels were observed in Neutrophils in all groups of dementia patients including the control group. Very high levels were observed in ESR in all groups of dementia patients. According to t-test, significant differences ( $p$-value $<0.0001$ ) were existed in the WBC levels between the control group and $A D$ as well as PD patients. A significant difference ( $p$-value $<0.0001$ ) existed in platelets between the control group and FTD patients. However, significant differences ( $p$-value $<0.0001$ ) existed for ESR in each group of dementia patients vs control group (Table 5).

\section{Comparison of Electrolytes}

Table 6 shows the mean values of sodium and potassium in each group of dementia patients including the control group. Normal values observed in all groups of dementia patients as well as in the control group. Significant differences existed for sodium and potassium levels between the control group and frontotemporal dementia cases ( $p$ values: $0.0011 \& 0.0009)$ (Table 7).

Table 4: Comparison of Mean Values of Leukocytes, Platelets \& ESR between of Dementia Patients and Controls.

\begin{tabular}{|c|c|c|c|c|}
\hline Leukocytes & $\begin{array}{l}\text { Control Group } \\
\qquad N=15\end{array}$ & $\begin{array}{c}\text { Alzheimer Disease (AD) } \\
\text { Patients } N=12\end{array}$ & $\begin{array}{l}\text { Parkinson's Disease } \\
\text { (PD) Patients } N=12\end{array}$ & $\begin{array}{c}\text { Frontotemporal } \\
\text { Dementia (FTD) } \\
\text { Patients } \mathrm{N}=11\end{array}$ \\
\hline $\begin{array}{l}\text { White Blood Cells } \\
\left(\times 10^{3} / \mathrm{mm}^{3}\right) \\
\text { Normal Range: } 4- \\
11 \times 10^{3} / \mathrm{mm}^{3}\end{array}$ & $7546.66 \pm 1044.62$ & $9442.85 \pm 901.03$ & $8654.54 \pm 1860.84$ & $8320.0 \pm 1599.16$ \\
\hline $\begin{array}{l}\text { Neutrophils (\%) } \\
\text { Normal Range: } 49 \text { - } 74\end{array}$ & $3.60 \pm 1.40$ & $4.14 \pm 1.40$ & $4.00 \pm 1.00$ & $3.50 \pm 1.17$ \\
\hline $\begin{array}{l}\text { Eosinophils (\%) } \\
\text { Normal Range: } 0-6\end{array}$ & $2.93 \pm 1.03$ & $3.28 \pm 1.20$ & $2.90 \pm 1.22$ & $2.50 \pm 1.08$ \\
\hline Platelets $\left(\times 10^{6} / \mathrm{L}\right)$ & $193620 \pm 40582.37$ & $199178.57 \pm 48574.92$ & $224818.18 \pm 46363.38$ & $25100 \pm 61029.04$ \\
\hline
\end{tabular}


Normal Range: $150-450$

ESR Normal Range: 0 - 10

$\left(\mathrm{mm} / 1^{\text {st }}\right.$ hour$)$

$12.06 \pm 4.13$

$117.35 \pm 7.94$

$106.72 \pm 10.14$

$80.70 \pm 10.77$

Table 5: Comparison of Leukocytes, Platelets \& ESR via. t-Test.

\begin{tabular}{|c|c|c|c|c|c|c|}
\hline \multirow[t]{2}{*}{ Leukocytes } & \multicolumn{2}{|c|}{$\begin{array}{l}\text { Control Group vs. Alzheimer } \\
\text { Disease (AD) Patients }\end{array}$} & \multicolumn{2}{|c|}{$\begin{array}{c}\text { Control Group vs. } \\
\text { Parkinson's Disease (PD) } \\
\text { Patients }\end{array}$} & \multicolumn{2}{|c|}{$\begin{array}{l}\text { Control Group vs. } \\
\text { Frontotemporal Dementia } \\
\text { (FTD) Patients }\end{array}$} \\
\hline & $p$ - value & $t$ - test; df & p-value & t- test & p-value & t- test \\
\hline White Blood Cells (/mm) & $<0.0001^{*}$ & $4.97 ; 25$ & $<0.0001^{*}$ & $1.95 ; 25$ & 0.148 & $1.49 ; 24$ \\
\hline Neutrophils (\%) & 0.3288 & $0.99 ; 25$ & 0.412 & $0.83 ; 25$ & 0.849 & $0.19 ; 24$ \\
\hline Eosinophils (\%) & 0.422 & $0.81 ; 25$ & 0.9453 & $0.069 ; 25$ & 0.313 & $1.03 ; 24$ \\
\hline Platelets & 0.745 & $0.32 ; 25$ & 0.0741 & $1.86 ; 25$ & $<0.0001^{*}$ & $8.46 ; 24$ \\
\hline ESR & $<0.0001^{*}$ & $44.51 ; 25$ & $<0.0001^{*}$ & $33.01 ; 25$ & $<0.0001^{*}$ & $22.65 ; 24$ \\
\hline
\end{tabular}

*significant

Table 6: Comparison of Mean Values of Sodium \& Potassium between of Dementia Patients and Controls.

\section{Electrolytes}

Sodium (mmol/L)

Normal Range: 136-145

Potassium ( $\mathrm{mmol} / \mathrm{L})$

Normal Range: 3.6-5.2

\section{Control Group $\mathbf{N}=15$}

$138.8 \pm 0.5$

$4.4 \pm 0.2$
Alzheimer Disease

(AD) Patients $\mathrm{N}=12$

$138.5 \pm 0.6$

$4.3 \pm 0.4$

$4.6 \pm 0.5$

$139 \pm 0.7$
Frontotemporal Dementia (FTD) Patients $\mathrm{N}=11$

(PD) Patients $\mathrm{N}=12$

$138 \pm 0.6$

$4.7 \pm 0.2$

Table 7: Comparison of Sodium \& Potassium via. t-Test.

\begin{tabular}{|c|c|c|c|c|c|c|}
\hline \multirow[t]{2}{*}{ Electrolytes } & \multicolumn{2}{|c|}{$\begin{array}{l}\text { Control Group vs. Alzheimer } \\
\text { Disease (AD) Patients }\end{array}$} & \multicolumn{2}{|c|}{$\begin{array}{c}\text { Control Group vs. Parkinson's } \\
\text { Disease (PD) Patients }\end{array}$} & \multicolumn{2}{|c|}{$\begin{array}{c}\text { Control Group vs. Frontotempora } \\
\text { Dementia (FTD) Patients }\end{array}$} \\
\hline & p-value & t- test; df & $p$-value & t- test & p-value & t- test \\
\hline Sodium (mmol/L) & 0.165 & $1.41 ; 25$ & 0.35 & $0.93 ; 25$ & 0.0011 & $3.70 ; 24$ \\
\hline $\begin{array}{l}\text { Potassium } \\
(\mathrm{mmol} / \mathrm{L})\end{array}$ & 0.404 & $0.84 ; 25$ & 0.16 & $1.41 ; 25$ & 0.0009 & $3.77 ; 24$ \\
\hline
\end{tabular}

\section{DISCUSSION}

The study reported that the mean of each erythrocyte (hemoglobin, hematocrit, RBC, mean cell volume-MCV, mean cell hemoglobin- $\mathrm{MCH}$ and $\mathrm{MCHC}$ ) was lower than the normal range. Whereas, the control group was having normal values of almost all parameters except, hematocrit and MCHC. Except for MCHC, the significant difference existed for each erythrocyte parameter between each dementia patient group (Alzheimer Disease-AD, Parkinson's Disease-PD, and Frontotemporal Dementia-FTD) and control group. Hemoglobin was associated with increased risks of microbleeds and consequently dementias in a number of studies. Winchester et al also ${ }^{16}$ reported low hemoglobin ranges in Alzheimer's disease. Although, poor cognitive function is reported from anemia, however, Winchester et $\mathrm{al}^{16}$ did not find any causative impact on cognitive performance from low red blood cells. Wolters et $\mathrm{al}^{17}$ mentioned the risk of dementia, including Alzheimer's, associated with both low and high serum levels of hemoglobin, as there were differences in the integrity of white matter and perfusion of cerebral tissue. Anemia is associated with the risk of developing any type of dementia in $34 \%$ 
and Alzheimer's dementia in $41 \%$ cases. ${ }^{18}$ In older persons, cognition was impaired in patients with higher or lower levels of hemoglobin, and the risk of developing Alzheimer's dementia was higher. ${ }^{19}$ We observed the normal ranges in white blood cells, eosinophils, and platelets in all groups of dementia patients including the control group. Low levels were observed in neutrophils in all groups of our dementia patients including the control group. Very high levels were observed in ESR in all groups of dementia patients. ESR tends to go up in advancing age and is more marked in females with dementia. Significant differences existed in the WBC levels between the control group and Alzheimer's cases as well as Parkinson's cases. A significant difference also existed in platelets between the control group and Frontotemporal dementia cases. We observed normal values in all groups of dementia patients as well as in the control group. Significant differences existed for sodium and potassium levels between the control group and frontotemporal dementia patients.

Dementia and cognitive impairment are secondary to cerebral infarction. Infarcts arise in the brain when there are vascular disturbances (embolism, spasms, bleeding, or low blood indices like hemoglobin or hematocrit). It is known that higher hemoglobin levels pose more risk of stroke than normal levels. As the age advances, there is more incidence of anemia ranging from as low as $4.2 \%$ to as high as $28 \%$. There is little literature to support this though ${ }^{20}$. With advancing age, the incidence of Alzheimer and other forms of dementia increases exponentially. The role of anemia as a cause of dementia is controversial. ${ }^{19} \mathrm{CBC}$ is generally advised in patients for identification of reversible dementia. Upon post mortem studies of demented human brains, the levels of potassium measured intracellularly were in contradiction to other studies. The raised intracellularK + were indicating exposure of astrocytes to $A \beta .{ }^{20}$ Cellular potassium was lower in other studies. ${ }^{21}$ When compared to other studies our study contradicts their results, as we had normal levels of sodium and potassium ions in the brain cells of demented patients. Our patients of the study were receiving treatment for their dementia. It is likely that correction of dementia brought the levels of these electrolytes back to normal. Dementia is found in patients that have either high or low hemoglobin. Cerebrovascular accidents cause dementia in these people who exhibit lower connectivity to brain infarcts. This, however, is still unclear, how hemoglobin relates to dementia. ${ }^{19}$ In Parkinson's disease, iron plays a significant role. It was found accumulated in the substantia nigra. ${ }^{21}$ Patients of PD were found to have a progressive reduction in hemoglobin content which also related to the peripheral metabolism of iron and indicated the severity of the disease. ${ }^{23}$ Inflammatory cytokines have a deleterious effect on erythropoietin leading to worsening of anemia with the increasing cytokine. ${ }^{24}$ The hematological indices and electrolytes show the level of cognitive dysfunction and it can also be used as a diagnostic biomarker for dementia progression in the patients of the South Punjab Population, but there is a limitation in our study that all patients were on the treatment for dementia.

\section{CONCLUSION}

We found deranged erythrocytes in cases of Alzheimer disease, Parkinson's disease and in frontotemporal dementia. Age related changes to hematological indices especially related to red blood cells, and inflammatory mediators like cytokines, hamper the microcirculation in the cerebral tissue leading to micro-infarcts or micro bleeds which cause neuronal insults and parenchymal damage, resulting in a progressive deterioration in cognition, memory, coordination and behavior of the individuals.

\section{RECOMMENDATION}

Adherence to the golden rules of health, physical activity and maintenance of healthy diet throughout life can lead to dementia free life. This was the study from single center on limited data. 


\section{LIMITATIONS OF THE STUDY}

Larger studies are required to establish the complete hematological profile of demented people.

\section{REFERENCES}

1. Wyss-Coray T. Ageing, neurodegeneration and brain rejuvenation. Nature, 2016; 539 (7628): 1806.

2. Bannach MA, Caetano ML, Teles Filho RV, Matozinho $\mathrm{HH}$, Morais LC, Cavalcante JE, Naves WN, Ramos AP, Souza WS. A literature review on dementia diagnosis. Journal of the Neurological Sciences, 2015; 357: e132.

3. Hendrie HC. Epidemiology of dementia and Alzheimer's disease. The American Journal of Geriatric Psychiatry, 1998 Mar 1; 6 (2): S3-18.

4. Ebly EM, Parhad IM, Hogan DB, Fung TS. Prevalence and types of dementia in the very old: results from the Canadian Study of Health and Aging. Neurology, 1994; 44 (9): 1593-.

5. Chapman DP, Williams SM, Strine TW, Anda RF, Moore MJ. PEER REVIEWED: Dementia and its implications for public health. Preventing Chronic Disease, 2006; 3 (2).

6. Fymat AL. On dementia and other cognitive disorders. Clinical Research in Neurology, 2019; 2 (1): 1-4.

7. Fymat AL. Immunotherapy of brain cancers and neurological disorders. J Cancer Prev Curr Res. 2017; 8 (6): 00301.

8. Cerejeira J, Lagarto L, Mukaetova-Ladinska E. Behavioral and psychological symptoms of dementia. Frontiers in Neurology, 2012; 3: 73.

9. Fymat AL. Neurological disorders and the blood brain barrier: 2. Parkinson and Other movement disorders. J Curr Opin Neurol Sci. 2018; 2: 362-83.

10. Fymat AL. Dementia: A review. J Clin Psychiatr Neurosci. 2018; 1 (3): 27-34.

11. Fymat AL. Alzheimer's disease: prevention, delay, minimization, and reversal. Clinical Research in Neurology, 2018; 1 (1): 1-6.

12. Al-Yaari SA, Al Hammadi FS, Alyami SA. Cortical \& Subcortical Dementias: A Psychoneurolinguistic Perspective.

13. Dawson TM, Dawson VL. Rare genetic mutations shed light on the pathogenesis of Parkinson disease. The Journal of Clinical Investigation, 2003; 111 (2): 145-51.

14. Grossman M. Frontotemporal dementia: a review. Journal of the International Neuropsychological Society: JINS. 2002; 8 (4): 566.

15. Kumar A, Singh A. A review on Alzheimer's disease pathophysiology and its management: an update. Pharmacological Reports, 2015; 67 (2): 195-203.

16. Winchester LM, Powell J, Lovestone S, NevadoHolgado AJ. Red blood cell indices and anaemia as causative factors for cognitive function deficits and for Alzheimer's disease. Genome Medicine, 2018; 10 (1): 1-2.

17. Wolters FJ, Zonneveld HI, Licher S, Cremers LG, Ikram MK, Koudstaal PJ, Vernooij MW, Ikram MA, Heart Brain Connection Collaborative Research Group. Hemoglobin and anemia in relation to dementia risk and accompanying changes on brain MRI. Neurology, 2019; 93 (9): e917-26.

18. Medical News Today. What to know about Alzheimer's disease. Available: Alzheimer's disease: Symptoms, stages, causes, and treatments (medicalnewstoday.com). 2021

19. Shah RC, Buchman AS, Wilson RS, Leurgans $S E$, Bennett DA. Hemoglobin level in older persons and incident Alzheimer disease: prospective cohort analysis. Neurology, 2011; 77 (3): 219-26.

20. Vitvitsky VM, Garg SK, Keep RF, Albin RL, Banerjee $\mathrm{R}$. $\mathrm{Na}+$ and $\mathrm{K}+$ ion imbalances in Alzheimer's disease. Biochimica et BiophysicaActa (BBA) Molecular Basis of Disease, 2012; 1822 (11): 167181.

21. Peters R, Burch L, Warner J, Beckett N, Poulter R, Bulpitt C. Haemoglobin, anaemia, dementia and cognitive decline in the elderly, a systematic review. BMC Geriatrics, 2008; 8 (1): 1-6.

22. Roberts $B R$, Doecke JD, Rembach $A$, Yévenes $L F$, Fowler CJ, McLean CA, Lind M, Volitakis I, Masters $\mathrm{CL}$, Bush Al, Hare DJ. Rubidium and potassium levels are altered in Alzheimer's disease brain and blood but not in cerebrospinal fluid. Actaneuropathologica communications. 2016; 4 (1): 1-8.

23. Reimao $S$, Ferreira $S$, Nunes RG, Pita Lobo $P$, Neutel D, Abreu D, Gonçalves N, Campos J, Ferreira JJ. Magnetic resonance correlation of iron content with neuromelanin in the substantia nigra of early-stage Parkinson's disease. European Journal of Neurology, 2016; 23 (2): 368-74. 
24. Grozdanov V, Bliederhaeuser C, Ruf WP, Roth V, Fundel-Clemens K, Zondler L, Brenner D, MartinVillalba A, Hengerer B, Kassubek J, Ludolph AC.
Inflammatory dysregulation of blood monocytes in Parkinson's disease patients. Actaneuropathologica. 2014; 128 (5): 651-63.

\section{Additional Information}

Disclosures: Authors report no conflict of interest.

Ethical Review Board Approval: The study was conformed to the ethical review board requirements.

Human Subjects: Consent was obtained by all patients/participants in this study.

Conflicts of Interest:

In compliance with the ICMJE uniform disclosure form, all authors declare the following:

Financial Relationships: All authors have declared that they have no financial relationships at present or within the previous three years with any organizations that might have an interest in the submitted work.

Other Relationships: All authors have declared that there are no other relationships or activities that could appear to have influenced the submitted work.

\section{AUTHORS CONTRIBUTIONS}

\begin{tabular}{|l|l|l|}
\hline Sr.\# & Author's Full Name & Intellectual Contribution to Paper in Terms of: \\
\hline 1. & Faiza Khalil & Study design and methodology. \\
\hline 2. & Noureen Samad & Paper writing, referencing, and data calculations. \\
\hline 3. & Sohaib Hassan & Data collection and calculations. \\
\hline 4. & Muhammad Ali Qureshi & Analysis of data and interpretation of results etc. \\
\hline 5. & Ahsan Numan & Literature review and manuscript writing. \\
\hline
\end{tabular}

